\title{
Intra-aortic metastases or intra-arterial thrombus?
}

\author{
Anna J Lomax, Saw Yee Yap, Mustafa Khasraw
}

\begin{abstract}
Introduction: Intra-arterial malignancies are difficult to diagnose as they mimic other more common pathologies such as pulmonary embolus and vascular occlusive disease. Appropriate treatment may, therefore, be delayed. Case Report: We report a case of an occluded carotid artery and aortic mucosal thickening with a peduculated thrombus occurring in a patient with metastatic sarcomatoid carcinoma while anticoagulated. Conclusion: Diagnosis requires various imaging modalities and a consideration of an alternative diagnosis if not responding to initial therapy.
\end{abstract}

Keywords: Intravascular metastases, Intraaortic metastases, Arterial thrombus, Sarcomatoid carcinoma

$* * * * * * * * *$

Lomax AJ, Yap SY, Khasraw M. Intra-aortic metastases or intra-arterial thrombus? International Journal of Case Reports and Images 2013;4(7):368-371.

doi:10.5348/ijcri-2013-07-333-7

Anna J Lomax ${ }^{1}$, Saw Yee Yap ${ }^{1}$, Mustafa Khasraw ${ }^{2}$

Affiliations: ${ }^{1}$ Oncology registrar Andrew Love Cancer Centre Geelong Hospital, Geelong VIC 3220, Australia; 2Oncologist, Andrew Love Cancer Centre, Geelong Hospital, Geelong VIC 3220, Australia.

Corresponding Author: Anna J Lomax, Andrew Love Cancer Centre, Geelong Hospital, Geelong VIC 3220, Australia; annalomax@y7mail.com

Received: 06 August 2012

Accepted: 23 February 2013

Published: 01 July 2013

\section{INTRODUCTION}

Arterial thrombosis caused by malignancy is less well described in literature compared to venous thromboembolism, which is a well recognized complication of cancer. A thrombotic phenomenon could also be the first manifestation of cancer. We report a patient with metastatic sarcomatoid carcinoma presenting with asymptomatic arterial thrombosis in his common carotid artery and aortic arch. The differential diagnosis included a spontaneous arterial thrombosis due to hypercoagulability, direct tumor invasion of arteries, fragmentation and embolization of intracardiac of tumor.

\section{CASE REPORT}

A 73-year-old male with metastatic sarcomatoid carcinoma underwent a restaging computed tomography (CT) scan that incidentally identified complete occlusion of the left common carotid at its origin and narrowing of the origin of the right brachiocephalic artery (Figure 1). Mucosal thickening was noted with dissection through the mucosa and atheromatous plaques in the aortic arch with a pedunculated $1.9 \mathrm{~cm}$ thrombus (Figure $2 \mathrm{~A}-\mathrm{B}$ ). The lesion was suspicious for metastasis.

This was in the setting of a supratherapeutic INR of 3.2 while anticoagulated with warfarin for atrial fibrillation. The left common carotid artery was patent on imaging performed two months earlier. A positron emission tomography (PET) scan confirmed increased metabolic activity in the adrenals and left 7 th rib but not in the aorta or left carotid. Magnetic resonance imaging (MRI) scan did not identify intracranial tumor.

Five months before, the patient underwent a resection and replacement of his proximal left humerus due to malignant infiltration. Histopathology revealed features of a malignant spindle cell neoplasm favoring metastatic sarcomatoid carcinoma rather than bone primary. However, the primary site was unknown. He was initially managed with postoperative radiotherapy to the surgical bed (20 Gy, 5 fractions) plus a boost to 


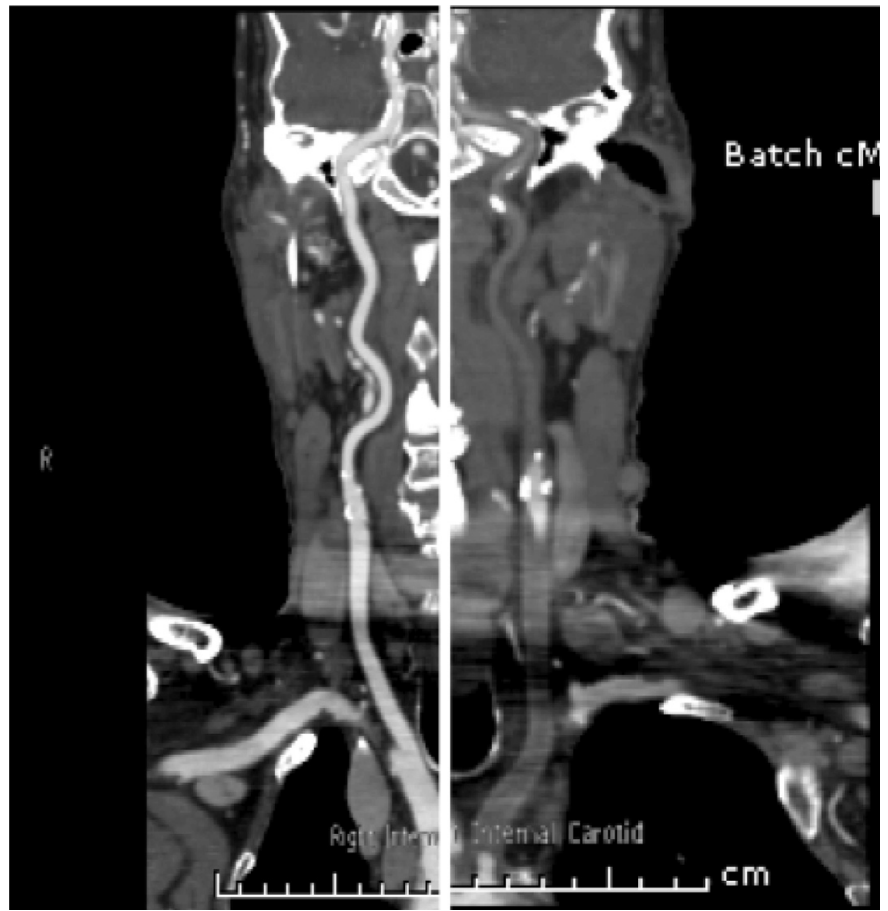

Figure 1: Normal right common carotid artery. Complete occlusion of the left common carotid artery.

the scar with a plan to follow with serial imaging. Other past history included significant peripheral vascular disease and diabetes. He was commenced on palliative intent chemotherapy with carboplatin and gemcitabine after the restaging scan. Warfarin was ceased and enoxaparin commenced. Left carotid embolectomy was deemed to be too risky. Prophylactic intervention to the right carotid was considered appropriate only if the patient were to have a good response to chemotherapy or became symptomatic of the stenosis.

\section{DISCUSSION}

Sarcomatoid carcinomas are uncommon tumors that are not specific to a particular anatomical site of origin. Features representative of carcinoma and sarcoma are present in variable proportions [1]. The carcinoma component consists of malignant epithelial cells whereas the sarcomatoid appearance is due to mesenchyme-like cells. This may occur through phenotypic conversion of carcinoma to sarcoma resulting in a more biphasic or monophasic tumor [1]. Those arising in a hollow organ may be pedunculated in appearance but can also have ulcerative or infiltrative chracteristics [1].

Carotid, aortic and pulmonary artery sarcomas (PAS) mimicking other pathologies such as vascular occlusive disease, aneurysms and pulmonary emboli are described in case reports [2-12]. Our patient represents a similar clinical scenario. The principles from these cases could be applied here.

Sarcomas of the aorta are rare and tend to involve the thoracic and abdominal aorta [11]. They may be
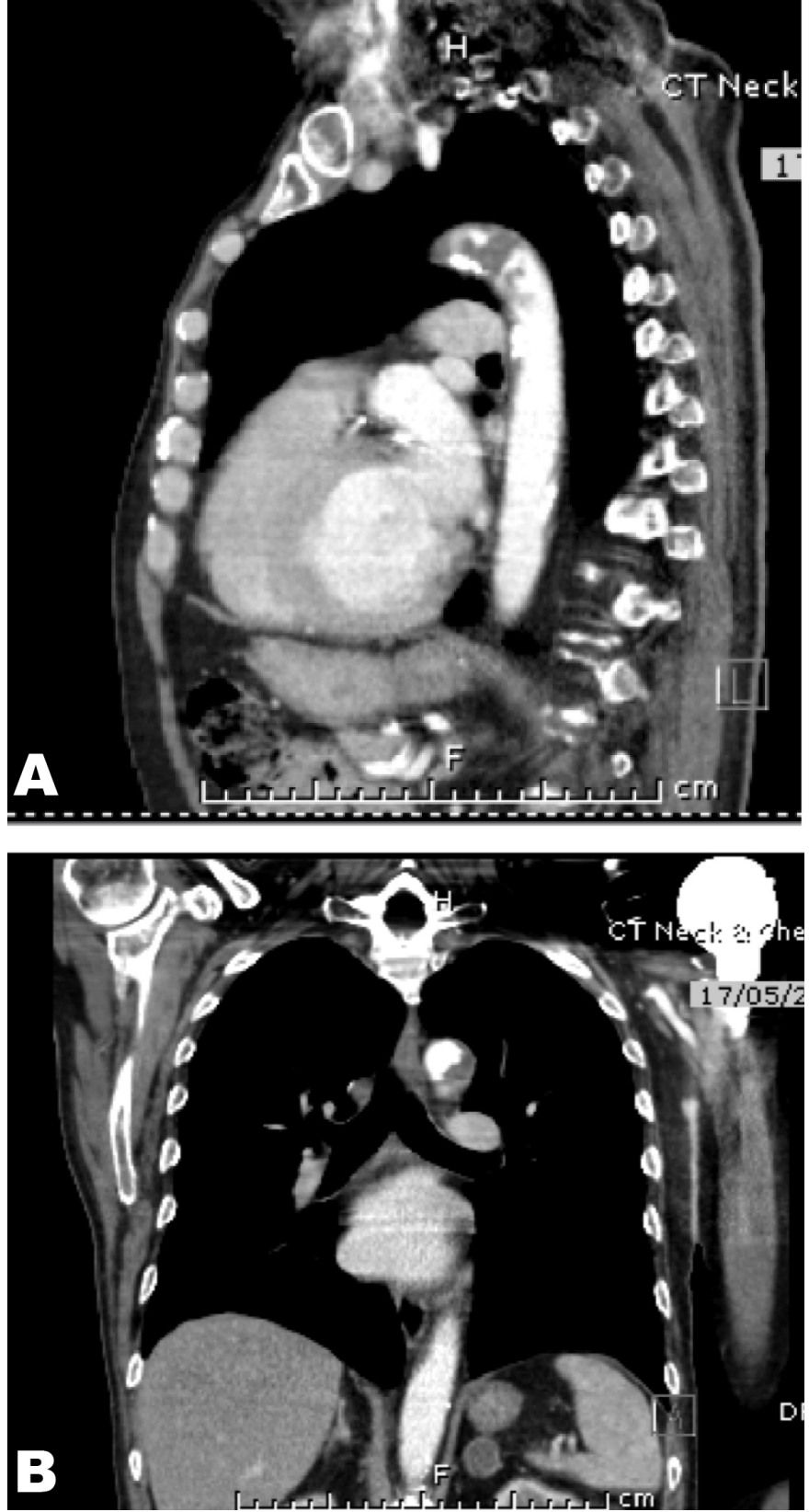

Figure 2: Pedunculated thrombus of the aortic arch (A) Sagittal view, (B) Coronal view.

intimal or mural. The former are more aggressive with plaque formation along the aorta or polypoid growth into the lumen, causing vessel occlusion and distal embolization. Mural sarcomas are less aggressive with invasion of surrounding structures $[3,6,11]$.

A paper examining the CT findings of pulmonary artery sarcoma and pulmonary emboli found some distinguishing features [13]. In PAS, a low-attenuation filling defect that occupies the entire luminal diameter of the main or proximal pulmonary artery was seen. There may be arterial expansion of the affected artery. Extra-luminal tumor extension may be present. Less common features include heterogenous enhancement and unilateral distribution.

An MRI with gadolinium-diethylenetriamine may aid diagnosis with enhancement of the filling defect 
Table 1: Summary of the features distinguishing intra-aortic tumor metastasis from arterial thrombus.

\begin{tabular}{lll}
\hline Distinguishing features & Intra-aortic metastasis & Intra-arterial thrombus \\
\hline Magnetic resonance imaging & $\begin{array}{l}\text { Enhancement of luminal filling } \\
\text { defect with gadolinium }\end{array}$ & $\begin{array}{l}\text { No enhancement if bland } \\
\text { thrombus }\end{array}$ \\
Positron emisson tomography & Avid & Not avid \\
Angiography & $\begin{array}{l}\text { Peduculated lesion with 'to and } \\
\text { fro' motion }\end{array}$ & \\
Computed tomography & $\begin{array}{l}\text { Arterial lumen occupied by } \\
\text { filling defect }\end{array}$ & $\begin{array}{l}\text { Incomplete filling defect of } \\
\text { arterial lumen }\end{array}$ \\
Response to anticoagulation & $\begin{array}{l}\text { Failure to improve (symptoms, } \\
\text { imaging) }\end{array}$ & Response \\
\hline
\end{tabular}

indicating intraluminal tumor. This would not occur if bland non-vascularized thrombus were present $[2,10$, 13].

The 18-fluoro-deoxyglucose (FDG)-PET/CT positive uptake has been demonstrated within a pulmonary artery sarcoma further aiding diagnosis and excluding bland thrombus $[2,4,14]$. The lack of PET enhancement in this case may be due to low volume of disease. Other factors supporting the diagnosis include a pedunculated or polypoid lesion with to and fro motion on angiography [7, 10]. This may not be apparent if there is a sessile tumor or excessive thrombus over the tumor [2].

Diagnosis may occur after failure of improvement in symptoms or a lack of response to anticoagulation on imaging [10, 12]. Diagnosis may be incidental after surgical intervention such as pulmonary thrombolectomy [10] and aneurysm repair [6]. The management of malignant intra-arterial disease involves a combination of resection or debulking, chemotherapy and radiotherapy $[7,14]$. Table 1 summarizes the features distinguishing intra-aortic metastasis from intra-arterial thrombus.

\section{CONCLUSION}

In summary, arterial vascular occlusion may be due to thrombosis or less commonly, direct tumor involvement requiring different medical management. Arterial malignancies are difficult to diagnose. Multimodality imaging such as computed tomography scan, magnetic resonance imaging scan, positron emission tomography is required and each provides additional information differentiating arterial malignancy from pure thrombus. Clinical factors, such as thrombus not responding to adequate anticoagulation and an index of suspicion, may prompt further investigation.

\section{Author Contributions}

Anna J Lomax - Substantial contributions to conception and design, Drafting the article, Final approval of the version to be published

Saw Yee Yap - Acquisition of CT images, Drafting the introduction, Final approval of the version to be published

Mustafa Khasraw - Contributions to conception and editing of article, Drafting the article, Final approval of the version to be published

\section{Guarantor}

The corresponding author is the guarantor of submission.

\section{Conflict of Interest}

Authors declare no conflict of interest.

\section{Copyright}

(C) Anna Lomax et al. 2013; This article is distributed under the terms of Creative Commons Attribution 3.0 License which permits unrestricted use, distribution and reproduction in any means provided the original authors and original publisher are properly credited. (Please see www.ijcasereportsandimages.com /copyright-policy.php for more information.)

\section{REFERENCES}

1. Guarino M, Paolo T, Giordano F, Cristofori E. Sarcomatoid Carcinomas: Pathological and Histopathogenetic Considerations. Pathology 1996;28(4):298-305.

2. Bressler EL, Nelson JM. Primary Pulmonary Artery Sarcoma: Diagnosis with CT, MR Imaging and Transthoracic Needle Biopsy. AJR Am J Roentgenol 1992;159(4):702-4.

3. Brylka D, Demos TC, Pierce K. Primary angiosarcoma of the abdominal aorta: a case report and literature review (aortic angiosarcoma). Abdom Imaging 2009;34(2):239-42. 
4. Chong S, Kim TS, Kim BT, Cho EY, Kim J. Pulmonary Artery Sarcoma Mimicking Pulmonary Thromboembolism: Integrated FDG PET/CT. AJR Am J Roentgenol 2007;188(6):1691-3.

5. Hottenrott G, Mentzel T, Peters A, Schröder A, Katenkamp D. Intravascular ("intimal") Epithelioid. Angiosarcoma: Clinicopathological and Immunohistochemical Analysis of Three Cases. Virchows Arch 1999;435(5):473-8.

6. Ishigami N, Suzuki K, Takahashi $T$, Neyatani $H$, Bashar AH, Kazui T. Intimal Sarcoma of Aortic Arch Treated with Proton Therapy Following Surgery. Asian Cardiovasc Thorac Ann 2008;16(2):e12-4.

7. Kathiravel Y, Westwood D, Macemon J, Singh H. An International Surgical Collaboration for the Management of Pulmonary Artery Sarcoma: a New Zealand Experience. The New Zealand Medical Journal 2007; 120(1257):U2609.

8. Mikami Y, Manabe T, Lie JT, Sakurai T, Endo K. Intramural Sarcoma of the Carotid Artery with Adventitial Inflammation and Fibrosis Resembling 'Inflammatory Aneurysm'. Pathology International 1997;47(8):569-74.

9. Nakahira A, Ogino H, Sasaki H, Katakami N. Longterm survival of a Pulmonary Artery Sarcoma Produced by Aggressive Surgical Resection and Adjuvant Chemoradiotherapy. European Journal of Cardio-thoracic Surgery 2007;32(2):388-90.
10. Rafal RB, Nichols JN, Markisz JA. Pulmonary Artery Sarcoma: Diagnosis and Postoperative Follow-up with Gadolinium-Diaethylenetramine Pentaacetic Acid-Enhance Magnetic Resonance Imaging. Mayo Clin Proc 1995;70(2):173-6.

11. Seelig MH, Klingler PJ, Oldenburg WA, Blackshear JL. Angiosarcoma of the Aorta: Report of a Case and Review of the Literature. J Vasc Surg 1998;28(4):732-7.

12. Singla Long S, Johnson PT, Hruban RH, Fishman EK. CT Features of Pulmonary Artery Sarcoma: Critical Aid to a Challenging Diagnosis. Emerg Radiol 2010;17(2):153-5.

13. Blackmon SH, Rice DC, Correa AM, et al. Management of Primary Pulmonary Artery Sarcomas. Ann Thorac Surg 2009;87(3):977-84.

14. Yi CA, Lee KS, Choe YH, Han D, Kwon OJ, Kim S. Computed Tomography in Pulmonary Artery Sarcoma. Distinguishing Features from Pulmonary Embolic Disease. J Comput Assist Tomogr 2004;28(1):34-9.
Access full text article on other devices

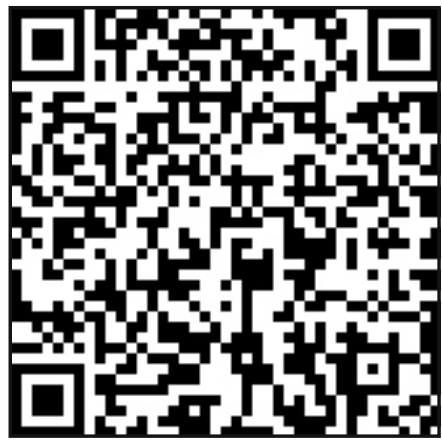

Access PDF of article on other devices

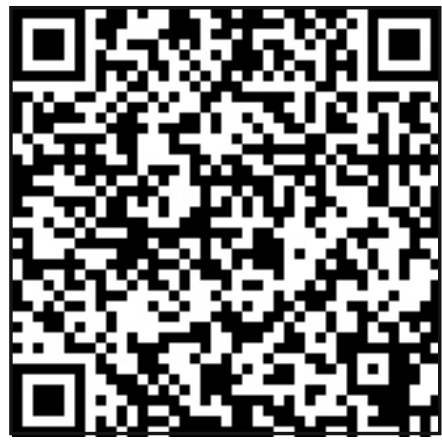

